\title{
PENGARUH PENYULUHAN TENTANG MENOPAUSE TERHADAP KECEMASAN SEKS MASA MENOPAUSE PADA KOMUNITAS MUSLIMATAN
}

\section{The Effect Of Menopause Education On Menopouse Sex Anxiety In The Muslimatan Community}

\author{
Iis Hanifah ${ }^{1}$, Tutik Hidayati ${ }^{2}$, Wahida Yuliana ${ }^{3}$
}

${ }^{1}$ Stikes Hafshawaty Pesantren Zainul Hasan

\section{Riwayat artikel}

Diajukan: Agustus 2021

Diterima: September 2021.

PenulisKorespondensi:

- Iis Hanifah

Stikes Hafshawaty

- Pesantren Zainul Hasan

- iishanifah2017@gmail .com

\section{Kata Kunci:}

Menopause, Kecemasan

Seks, Komunitas

muslimatan

\begin{abstract}
Abstrak
Perubahan fisiologis akibat menopause kadang-kadang mengganggu aktivitas dan gairah seksual pada sejumlah wanita.Karena perubahan-perubahan tersebut mengakibatkan kegiatan seksual menjadikurang menyenangkan. Tahun 2019, jumlah lansia Indonesia diproyeksikan akan meningkat menjadi 27,5 juta atau $10,3 \%$, dan 57,0 juta jiwa atau 17,9\% pada tahun 2045 (BPS, Bappenas, UNFPA, 2018). Berdasarkan data Survey Penduduk antar Sensus (Supas) 2015, Jumlah lanjut usia Indonesia sebanyak 21,7 juta atau 8,5\%. Penduduk lansia di Jawa Timur pada tahun2017 telah mencapai 12,92 persen yang menandakan bahwa struktur penduduk JawaTimur tergolong penduduk tua. Desain penelitian yang digunkan pra experimental tanpa ada kelompok control dengan menggunkan pendekatan one group pretest-post-test design. Pengumpulan data menggunkan kuesioner Hasil uji Wilcoxon tentang pengaruh penyuluhan tentang menopause terhadap kecemasan seks masa menopause pada komunitas muslimatan. diperoleh nilai $\mathrm{p}$ value $=0.002>0,05$, maka ha diterima sehingga ada pengaruh penyuluhan tentang menopause terhadap kecemasan seks masa menopause pada komunitas muslimatan.
\end{abstract}

Physiological changes due to menopause sometimes interfere with sexual activity and arousal in some women. Because these changes make sexual activity less enjoyable. In 2019, the number of elderly people in Indonesia is projected to increase to 27.5 million or $10.3 \%$, and 57.0 million people or 17.9\% in 2045 (BPS, Bappenas, UNFPA, 2018). Based on data from the 2015 Inter-Census Population Survey (Supas), the number of elderly people in Indonesia is 21.7 million or $8.5 \%$. The elderly population in East Java in 2017 has reached 12.92 percent which indicates that the population structure of East Java is classified as an elderly population. The research design used was pre-experimental without a control group by using a one-group pretest-post-test design approach. Data collection using a questionnaire Wilcoxon test results about the effect of counseling about menopause on menopausal sex anxiety in the Muslim community. obtained $p$ value $=0.002>0.05$, then ha is accepted so that there is an effect of counseling about menopause on menopausal sex anxiety in the Muslim community 


\section{Pendahuluan}

Menopause adalah berakhirnya siklus menstruasi secara alami, yang biasanya terjadi saat wanita memasuki usia 45 hingga 55 tahun. Perubahan fisiologis akibat menopause kadangkadang mengganggu aktivitas dan gairah seksual pada sejumlah wanita.Karena perubahan-perubahan tersebut mengakibatkan kegiatan seksual menjadikurang menyenangkan (Qomariati., 2013). Tahun 2019, jumlah lansia Indonesia diproyeksikan akan meningkat menjadi 27,5 juta atau $10,3 \%$, dan 57,0 juta jiwa atau $17,9 \%$ pada tahun 2045 (BPS, Bappenas, UNFPA, 2018). Berdasarkan data Survey Penduduk antar Sensus (Supas) 2015, Jumlah lanjut usia Indonesia sebanyak 21,7 juta atau $8,5 \%$. Penduduk lansia di Jawa Timur pada tahun2017 telah mencapai 12,92 persen yang menandakan bahwa struktur penduduk JawaTimur tergolong penduduk tua. Penduduk lansia mempunyai karakter sosial ekonomi yang berbeda dibanding dengan penduduk muda, sehingga membutuhkan perhatian khusus bagi para pengambil kebijakan agar arah pembangunan dapat bermanfaatmaksimal bagi penduduk lansia (Badan Pusat Statistik,2019). Hasil Studi pendahuluan yang dilakukan kepada ibu usia pra menopause yang berjumlah 10 wanita dari 10 wanita tidak mengetahui perubahan pada masa menopause nanti. Hal ini menjadi permasalahan jika ibu sudah memasuki masa menopause dan mengalami perubahan fisik hasil wawancara menyebutkan bahwa ibu ibu belum memiliki komunitas untuk mendiskusikan informasi mengenai perubahan fisiologis masa menopause.

Faktor yang berpengaruh secara signifikan terhadap tingkat kecemasan pada wanita perimenopause adalah pengetahuan, sikap, dan dukungan keluarga. Seorang wanita menopause membutuhkan cukup informasi melalui konsultasi dengan anggota keluarga terdekat, teman bahkan dokter untuk mendapatkan informasi yang benar dan menjalani masa menopause dengan gaya hidup yang sehat dan berpikiran positif agar dapat menghindari kecemasan itu sendiri (Muniroh \& mahmuda, 2013)

Masalah perubahan dalam masa menopause ini perlu adanya sebuah kelompok sesama wanita lansia untuk bisa saling bercerita dan berbagi pengetahuan. Dengan adanya sebuah komunitas yang sama maka wanita lebih mudah untuk mendiskusikan masalah seks dimasa menopause sehingga harapannya tidak ada lagi kecemasan. Tujuan penelitian ini yaitu untuk mengetahui Mengidentifikasi kecemasan seks masa menopause sebelum dilakukan penyuluhan di Desa Gading, mengidentifikasi kecemasan seks masa menopause sesudah dilakukan penyuluhan di Desa Gading dan menganalisis pengaruh penyuluhan tentang menopause terhadap kecemasan seks masa menopause pada komunitas muslimatan di Desa Gading.

\section{Metodologi}

Desain penelitian yang digunakan adalah Pra experimental tanpa kelompok kontrol dengan menggunakan pendekatan one group pretest-postest design. Populasi pada penelitian ini yaitu Seluruh wanita yang berusia 40-45 tahun yang belum mengalami menopause pada komunitas muslimatan di Desa Gading berjumlah 50 orang. Sampling: Menggunakan Simple Random. Untuk mengukur kecemasan seks masa menopause menggunakan kuesioner. Analisis Data pada penelitian ini yaitu analisis Univariat menggunakan distribusi frekuensi. Analisis Bivariat menggunakan Wilcoxon

\section{Hasil dan Pembahasan}

Dalam data umum ini disajikan mengenai data-data umum dari sampel penelitian penelitian" pengaruh 


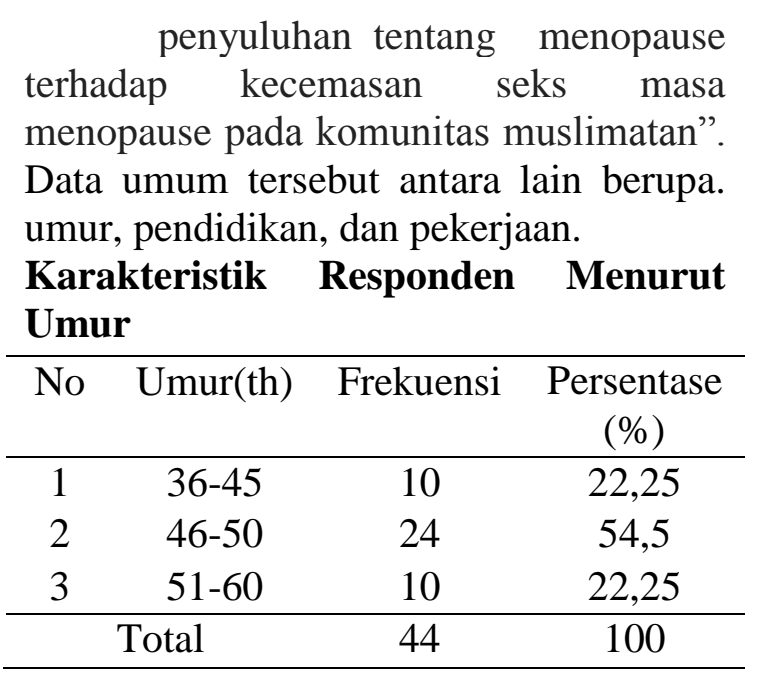

Berdasarkan tabel diatas diketahui bahwa sebagian besar responden berumur 46-50 tahun sebanyak 24 orang $(54,5 \%)$

\begin{tabular}{cccc}
$\begin{array}{l}\text { Karakteristik } \\
\text { Pendidikan }\end{array}$ & Responden & Menurut \\
\hline No & Pendidikan & Frekuensi & $\begin{array}{c}\text { Persentase } \\
(\%)\end{array}$ \\
\hline 1 & Tidak & 17 & 38,6 \\
& Sekolah & & \\
2 & SD/MI & 8 & 18,2 \\
3 & SMP/MTS & 9 & 20,5 \\
4 & SMA/MA & 10 & 22,7 \\
5 & Sarjana & 0 & 0 \\
\hline & Total & 44 & 100 \\
\hline
\end{tabular}

Berdasarkan tabel diatas bahwa pendidikan terakhir ibu adalah tidak sekolah sebanyak 17 orang $(38,6 \%)$.

\section{Karakteristik Responden Menurut} Pekerjaan

\begin{tabular}{cccc}
\hline No & $\begin{array}{c}\text { Pekerjaan } \\
\text { Orang }\end{array}$ & Frekuensi & $\begin{array}{c}\text { Persentase } \\
(\%)\end{array}$ \\
& Tua & & \\
\hline 1 & Swasta & 9 & 20,5 \\
2 & IRT & 35 & 79,5 \\
\hline & Total & 44 & 100 \\
\hline
\end{tabular}

Berdasarkan tabel diatas diketahui bahwa pekerjaan ibu adalah ibu rumah tangga sebanyak 35 orang $(79,5 \%)$.

\section{Kecemasan menghadapi seks menopause Sebelum Dilakukan Penyuluhan tentang menopause}

\begin{tabular}{|c|c|c|}
\hline $\begin{array}{l}\text { Tingkat } \\
\text { Kecemasan }\end{array}$ & $\begin{array}{c}\text { Frekuen } \\
\text { si }\end{array}$ & Prosentase \\
\hline Tidak ada kecemasan & 3 & $6,8 \%$ \\
\hline Kecemasan ringan & 9 & $20,5 \%$ \\
\hline Kecemasan sedang & 13 & $29,5 \%$ \\
\hline Kecemasan berat & 19 & $43,2 \%$ \\
\hline Jumlah & 44 & $100 \%$ \\
\hline
\end{tabular}

Berdasarkan tabel diatas diketahui kecemasan menghadapi seks menopause sebelum dilakukan penyuluhan tentang menopause sebagian besar mengalami kecemasan berat sebanyak $19 \mathrm{ibu}(43,2 \%)$.

\section{Kecemasan menghadapi seks menopause Sesudah Dilakukan Penyuluhan tentang menopause}

\begin{tabular}{lcc}
\hline $\begin{array}{l}\text { Tingkat } \\
\text { Kecemasan }\end{array}$ & $\begin{array}{c}\text { Frekuen } \\
\text { si }\end{array}$ & Prosentase \\
\hline $\begin{array}{l}\text { Tidak ada } \\
\text { kecemasan }\end{array}$ & 23 & $52,3 \%$ \\
$\begin{array}{l}\text { Kecemasan } \\
\text { ringan }\end{array}$ & 12 & $27,3 \%$ \\
$\begin{array}{l}\text { Kecemasan } \\
\text { sedang }\end{array}$ & 7 & $16,0 \%$ \\
$\begin{array}{l}\text { Kecemasan berat } \\
\text { Jumlah }\end{array}$ & 2 & $4,4 \%$ \\
& 44 & $100 \%$
\end{tabular}

Berdasarkan tabel diatas diketahui kecemasan menghadapi seks menopause sesudah dilakukan penyuluhan tentang menopause sebagian besar tidak mengalami kecemasan sebanyak $23 \mathrm{ibu}$ $(52,3 \%)$. 
Pengaruh penyuluhan tentang menopause terhadap kecemasan seks masa menopause pada komunitas muslimatan di Desa Gading.

\begin{tabular}{|c|c|c|c|c|c|c|}
\hline \multirow{3}{*}{$\begin{array}{c}\text { Tingkat } \\
\text { Kecemasan }\end{array}$} & \multicolumn{6}{|c|}{ Penyuluhan tentang menopause } \\
\hline & \multicolumn{2}{|c|}{$\begin{array}{l}\text { Sebelum } \\
\text { penyuluha } \\
n\end{array}$} & \multicolumn{2}{|c|}{$\begin{array}{c}\text { Sesudah } \\
\text { Penyuluhan }\end{array}$} & \multicolumn{2}{|c|}{$\begin{array}{c}\text { Peningka } \\
\tan \end{array}$} \\
\hline & $\mathrm{F}$ & $\%$ & $\mathrm{~F}$ & $\%$ & $\mathrm{~F}$ & $\%$ \\
\hline $\begin{array}{l}\text { Tidak ada } \\
\text { kecemasan }\end{array}$ & 3 & 6,8 & $\begin{array}{l}2 \\
3\end{array}$ & 52,3 & 20 & 87,0 \\
\hline $\begin{array}{c}\text { Kecemasan } \\
\text { Ringan }\end{array}$ & 9 & 20,5 & $\begin{array}{l}1 \\
2\end{array}$ & 27,3 & 3 & 13,0 \\
\hline $\begin{array}{c}\text { Kecemasan } \\
\text { Sedang }\end{array}$ & $\begin{array}{l}1 \\
3\end{array}$ & 29,5 & 7 & 16,0 & & \\
\hline $\begin{array}{c}\text { Kecemasan } \\
\text { Berat }\end{array}$ & & 43,2 & 2 & 4,4 & & \\
\hline Jumlah & 44 & 100,0 & 40 & 100,0 & 23 & $\begin{array}{r}100, \\
0\end{array}$ \\
\hline$Z=-$ & & $\mathrm{Va}$ & $=0$ & & & \\
\hline
\end{tabular}

Berdasarkan tabel 5.6 kecemasan seks menopause sebelum dilakukan penyuluhan, sebagian besar mengalami kecemasan berat sebanyak 19 ibu $(43,2 \%)$. Sedangkan kecemasan seks menopause sesudah dilakukan penyuluhan pada sebagian besar tidak mengalami kecemasan sebanyak $23 \mathrm{ibu}$ $(52,3 \%)$. Hasil analisa bivariat menunjukkan nilai $\mathrm{p}$ value $=0.002>0,05$, menunjukkan ada Pengaruh penyuluhan tentang menopause terhadap kecemasan seks masa menopause pada komunitas muslimatan di Desa Gading

\section{Tingkat Kecemasan Ibu dalam Menghadapi Menopause Sebelum Penyuluhan}

Berdasarkan tabel 5.5 diketahui kecemasan menghadapi seks menopause sebelum dilakukan penyuluhan tentang menopause sebagian besar mengalami kecemasan berat sebanyak 19 ibu $(43,2 \%)$. Kecemasan yang muncul pada wanita menopause sering dihubungkan dengan adanya kekhawatiran

dalam menghadapi suatu situasi yang sebelumnya tidak pernah dikhawatirkan. Adanya keragaman dan perbedaan tingkat kecemasan ibu dalam menghadapi menopause dapat disebabkan oleh beberapa faktor. Kecemasan yang terjadi pada seseorang tidak sama pada beberapa situasi. Kecemasan yang terjadi dipengaruhi oleh salah satu faktor ancaman terhadap integritas diri yang meliputi ketidak mampuan fisiologis atau gangguan terhadap kebutuhan dasar seperti penyakit fisik dan menilai kecemasan sebagai pengalaman subyektif yang mungkin didasarkan atas persepsi terhadap situasi yang terjadi( Stuart, 2007). Ibu yang mengalami periode premenopause, munculnya masalah psikologis sangat dipengaruhi oleh adanya perubahan pada aspek fisik fisiologis sebagai akibat dari berkurang dan berhentinya produksi hormon estrogen, karena berkurangnya hormon inilah yang menimbulkan berbagai gejala dan keluhan(. Kenyataannya tidak semua perempuan mengalami kecemasan, ketakutan saat menghadapi premenopause. Ada perempuan yang tidak merasakan adanya gangguan pada kondisi psikisnya. Berat ringannya stres yang dialami perempuan dalam menghadapi dan mengatasi premenopause sangat dipengaruhi oleh bagaimana penilaiannya terhadap premenopause (Kusworo, 2011).

\section{Tingkat Kecemasan Ibu dalam Menghadapi Menopause Sesudah Penyuluhan}

Berdasarkan tabel diatas diketahui kecemasan menghadapi seks menopause sesudah dilakukan penyuluhan tentang menopause sebagian besar tidak mengalami kecemasan sebanyak 23 ibu $(52,3 \%)$. Hal ini disebabkan ibu telah mengetahui bahwa menopause merupakan peristiwa alamiah dan konsekuensi dari proses penuaan, menurunnya fungsi organ bahkan berhentinya produksi hormon estrogen. Ibu premenopause harus menghadapinya 
dengan penuh tawakal, keikhlasan, dan sikap positif. Ibu premenopause juga telah siap menghadapi gejolak-gejolak psikologis akibat menopause.

Pendidikan kesehatan tentang menopause merupakan salah satu sumber informasi bagi responden sehingga tidak terjadi kecemasan dalam menghadapi menopause. Informasi yang diperoleh tentang suatu objek akan berpengaruh terhadap sikap objek tersebut. Adanya keragaman tingkat kecemasan dalam menghadapi menopause meskipun sudah dilakukan penyuluhan tentang menopause disebabkan karena faktor dari individu. Menurut Kasdu (2008), sikap dan kesiapan seseorang wanita dalam mempersiapkan dan mengatasi sesuatu hal yang terjadi antara individu yang satu dan yang lainnya berbeda-beda, seperti halnya kesiapan dalam menghadapi menopause.

\section{Pengaruh penyuluhan tentang menopause terhadap kecemasan seks masa menopause pada komunitas muslimatan di Desa Gading}

Berdasarkan tabel diatas kecemasan seks menopause sebelum dilakukan penyuluhan, sebagian besar mengalami kecemasan berat sebanyak 19 ibu $(43,2 \%)$. Sedangkan kecemasan seks menopause sesudah dilakukan penyuluhan pada sebagian besar tidak mengalami kecemasan sebanyak $23 \mathrm{ibu}$ $(52,3 \%)$. Hasil analisa bivariat menunjukkan nilai $\mathrm{p}$ value $=$ $0.002>0,05$, menunjukkan ada Pengaruh penyuluhan tentang menopause terhadap kecemasan seks masa menopause pada komunitas muslimatan di Desa Gading

Pendidikan kesehatan melalui penyuluhan ini merupakan suatu proses yang bertujuan untuk mempengaruhi pengetahuan, sikap dan perilaku yang ada hubungannya dengan kesehatan perorangan ataupun kelompok. Hal ini dibuktikan dengan penelitian yang telah dilakukan oleh peneliti, yaitu ibu yang memiliki penurunan tingkat kecemasan berat dan sedang menjadi kecemasan ringan hingga ibu tidak mengalami cemas. Selain itu, didukung oleh teori menurut Azril Azwar dalam Nugroho dan Ari (2010), mengatakan bahwa penyuluhan adalah kegiatan pendidikan yang dilakukan dengan cara menyebarkan pesan, menanamkan keyakinan sehingga masyarakat tidak saja sadar, tahu, dan mengerti, tetapi juga mau dan bisa melakukan suatu anjuran yang ada hubungan dengan kesehatan.

\section{Simpulan}

Kecemasan menghadapi seks menopause sebelum dilakukan penyuluhan tentang menopause sebagian besar mengalami kecemasan berat sebanyak 19 ibu (43,2\%). kecemasan menghadapi seks menopause sesudah dilakukan penyuluhan tentang menopause sebagian besar tidak mengalami kecemasan sebanyak 23 ibu (52,3\%).

Kecemasan seks menopause sebelum dilakukan penyuluhan, sebagian besar mengalami kecemasan berat sebanyak 19 ibu (43,2\%). Sedangkan kecemasan seks menopause sesudah dilakukan penyuluhan pada sebagian besar tidak mengalami kecemasan sebanyak 23 ibu (52,3\%). Hasil analisa bivariat menunjukkan nilai $\mathrm{p}$ value $=$ $0.002>0,05$, menunjukkan ada Pengaruh penyuluhan tentang menopause terhadap kecemasan seks masa menopause pada komunitas muslimatan di Desa Gading.

\section{Daftar Pustaka}

Ari kusworo. 2011. Pengaruh Pendidikan Kesehatan Tentang Menopause Terhadap Tingkat Kecemasan Ibu Usia 40-50 Tahun Dalam Menghadapi Menopause Di RT O8 Pendukuhan IX Ngestiharjo Kasihan Bantul. Sekolah Tinggiilmu Kesehatan Aisyiyah Yogyakarta 
Badan Pusat Statistik. (2018). Agustus 2018: Tingkat Pengangguran Terbuka (TPT) sebesar 5,34 Persen. Diakses dari

https://www.bps.go.id/pressrelease/20

18/11/05/1485/agustus-2017--

tingkatpengangguran-terbuka--tpt--

sebesar-5-34-persen.html pada tanggal

20 januari 2020, Jam 12.25 WIB.

Baziad, Ali. 2003. Menopause Dan

Andropause. Jakarta : Yayasan Bina

Pustaka

Sarwono Prawiroharjo.

Muniroh \& mahmuda, 2013. Faktor yang Berpengaruh terhadap Skor Kecemasan pada Wanita Menopause journal.unair.ac.id

Stuart, G. W. 2007. Buku Saku Keperwatan Jiwa. Edisi 5. Jakarta : EGC.

Qomariati, Arbaini. 2013.Hubungan Kecemasan dan Aktivitas Fisik dengan Kehidupan Seksual pada Wanita Menopause di Kelurahan Sajen Wilayah Kerja Puskesmas Trucuk I Kabupaten Klaten.urnal Kesehatan Masyarakat Universitas Diponegoro • 2013. volume 2, Nomor 1, Januari 2013 Online di http://ejournals1.undip.ac.id/index.php /jkm

Qorina Dzurrotul. Dkk. (2015). Peranan Muslimat dalam Pemberdayaan Perempuan di Bidang Sosial Keagamaan di Batang Tahun 19982010. Journal of Indonesian History 4 (1) (2015). 